\title{
Early Improved and Late Defective Cognition Is Reflected by Dendritic Spines in Tau.P301L Mice
}

\author{
Anna Kremer, Hervé Maurin, David Demedts, Herman Devijver, Peter Borghgraef, and Fred Van Leuven \\ Laboratory of Experimental Genetics and Transgenesis/Experimental Genetics Group, Department of Human Genetics, Katholieke Universiteit Leuven, \\ Campus Gasthuisberg, B-3000 Leuven, Belgium
}

Cognitive demise correlates with progressive brain tauopathy in dementing patients. Improved cognition of young Tau.P301L mice contrasts with dysfunction later in life and remains unexplained (Boekhoorn et al., 2006). To unravel early mechanisms, we composed a correlative time line of clinical symptoms, cognitive defects, and biochemical and pathological traits, including comprehensive analysis of dendritic spines in specified regions of the cortex and hippocampus of young and adult Tau.P301L mice. Remarkably, young Tau.P301L mice have not more, but more mature spines than wild-type mice, revealing the anatomical substrate for their improved cognition and LTP. Spine maturation remained high in the hippocampus of adult Tau.P301L mice. However, spines regressed in length paralleling impaired cognition and increased Tau phosphorylation (Terwel et al., 2005). Conversely, spine maturation was unaffected in adult Tau.4R mice, while spine density was increased and length reduced similar to Tau.P301L mice. To explain how protein Tau promoted spinogenesis, we analyzed hippocampal synaptosomes and dendritic spines for mouse and human Tau. While synaptosomes were positive for both mouse and human Tau, weak variable reaction in spines was observed only after fixation according to Bouin. Mouse Tau was absent from spines in wild-type mice, dissociating the pathological actions of Tau in transgenic mice by relocalization into dendrites and spines from the physiological actions of protein Tau in axons only. We conclude that mutant protein Tau modulates cognition and morphology of spines similarly and in both directions, with pathology later in life coinciding with increased phosphorylation and relocalization of Tau from axons to soma and processes.

\section{Introduction}

Tauopathies are a broad class of neurodegenerative diseases characterized by aggregates of protein Tau in different regions and types of neurons, the basis of postmortem diagnosis and differentiation (for review, see Delacourte and Buée, 2000; Ingram and Spillantini, 2002; Duyckaerts et al., 2009; Ludolph et al., 2009). Conversely, various mutations in gene coding for Tau cause a subtype of frontotemporal dementia clinically similar to Alzheimer's disease $(\mathrm{AD})$, although $\mathrm{AD}$ is a secondary tauopathy.

The transient state known as mild cognitive impairment (MCI) is neither a disease nor an obligatory intermediate to dementia because individuals convert at very different rates; some never become demented, while others even revert. In $\mathrm{AD}$, spatial and temporal patterns not of amyloid but of tauopathy correlate with cognitive decline (Braak and Braak, 1991; Delacourte and

\footnotetext{
Received Sept. 23, 2011; accepted 0ct. 20, 2011.

Author contributions: A.K., H.M., and F.V.L. designed research; A.K., H.M., D.D., H.D., and P.B. performed research; A.K., H.M., D.D., H.D., P.B., and F.V.L. analyzed data; A.K., P.B., and F.V.L. wrote the paper.

The investigations were made possible by funding and infrastructural support from the Fonds voor Wetenschappelijk Onderzoek-Vlaanderen, Instituut Wetenschap \& Techniek, The European Union Sixth and Seventh Framework Programmes, the de Rooms-Fund, the Katholieke Universiteit Leuven Research Fund, and Katholieke Universiteit Leuven Research \& Development. A.K. and H.M. gratefully acknowledge the support provided by Marie Curie doctoral fellowships (Marie Curie Early Training Site contract number 2005-020013 NEURAD). We thank many collaborators and scientists for technical assistance, advice, materials, and scientific and moral support.

Correspondence should be addressed to Fred Van Leuven, Laboratory of Experimental Genetics and Transgenesis/Experimental Genetics Group, Department of Human Genetics, Katholieke Universiteit Leuven, Campus Gasthuisberg 0N1-06.602, Herestraat 49, B-3000 Leuven, Belgium. E-mail: fred.vanleuven@med.kuleuven.be.

DOI:10.1523/JNEUROSCI.4859-11.2011

Copyright $\odot 2011$ the authors $\quad 0270-6474 / 11 / 3118036-12 \$ 15.00 / 0$
}

Buée, 2000; Delacourte, 2008). Immunohistochemistry (IHC) for phosphorylated protein Tau with antibody AT8 benchmarks the pathological progression of AD (Braak and Braak, 1991). Of note, operational implementation of AT8 in pathology does not define the specified phosphorylations as pathological because AT8 reaction is evident physiologically in development and the adult brain, in humans and animals, and in normal conditions, hibernation, and hypothermia (Kenessey and Yen, 1993; Takuma et al., 2003; Härtig et al., 2005, 2007; Planel et al., 2009; Braak and Del Tredici, 2011; Duyckaerts, 2011).

Here, we analyzed dendritic spines in Tau.P301L mice in the context of the time line of clinical symptoms, cognitive defects, and biochemical and pathological traits. In contrast to amyloid effects (Penzes et al., 2011), studies of Tau and spines in vivo are needed. Other studies used ex vivo sections transduced to express EGFP-Tau (Tackenberg and Brandt, 2009), injection of dyes (Dickstein et al., 2010; Rocher et al., 2010), or in vivo microscopy (Bittner et al., 2010). Others were restricted to primary neurons, transfected or transduced (Thies and Mandelkow, 2007; Hoover et al., 2010; Zempel et al., 2010). We combined our validated Tau.P301L and Tau.4R mice with yellow fluorescent protein (YFP) mice (Spittaels et al., 2000; Terwel et al., 2005). Technical advantages are obvious: no manipulation of brain or sections postmortem and no restriction to single area or layer. This study is the first to analyze systematically the effects of protein Tau on dendritic spines in four specified brain regions relevant for tauopathy and $\mathrm{AD}$.

We describe the impact of protein Tau on density and morphology of spines, both positively and negatively. Unexpectedly, 
in young Tau.P301L mice, the increased spine maturation explains their improved cognition and LTP (Boekhoorn et al., 2006). Synaptosomes contained both endogenous mouse and transgenic human protein Tau. Mutant protein Tau distributed diffusely throughout the cytoplasm in somata and processes, including presynaptic and postsynaptic compartments. Conversely, wild-type murine protein Tau was immunohistochemically detectable mainly in axons and not in dendritic spines. The combined data dissociate the pathological action of Tau in transgenic mice in dendrites and spines from the physiological actions of Tau in axons: mutant protein Tau modulates cognition and morphology of spines similarly, and in both directions, depending on phosphorylation and relocalization to processes.

\section{Materials and Methods}

Transgenic mice. Two transgenic mouse models expressing either Tau.P301L or Tau.4R (Spittaels et al., 1999; Terwel et al., 2005) were crossed with the transgenic Thyl-YFP mouse strain with relatively low expression of the fluorescent protein (Feng et al., 2000). Offspring were genotyped for human protein Tau transgenes and for the YFP transgene by standard PCR methods on DNA isolated from tail biopsy (Spittaels et al., 1999; Feng et al., 2000; Terwel et al., 2005).

Dendritic spine analysis. Spines were analyzed by confocal microscopy (Olympus Fluoview 1000) in four different brain regions, i.e., stratum radiatum (SR), stratum oriens (SO), and cortical layer III above the striatum (CS) and above the hippocampus (CH) (Fig. 2A). In total, 12 independent images per mouse, and five mice per genotype per age time point, resulted in the analysis of 57,870 spines on an overall length of $45.37 \mathrm{~mm}$ dendrites. At age 1-2 months, we analyzed $\sim 14,000$ WT.YFP spines on a total length of $11.53 \mathrm{~mm}$ dendrites and 12,569 spines in Tau.P301LxYFP mice over $10.19 \mathrm{~mm}$ dendrite length. At age 4-6 months, 10,187 WT.YFP spines were counted and analyzed on $8.45 \mathrm{~mm}$ of dendrites, with 10,958 spines in Tau.P301LxYFP mice on $8.04 \mathrm{~mm}$ of dendrites and 10,156 spines in Tau.4RxYFP mice on $7.16 \mathrm{~mm}$ of dendrites. The analysis was based on projection images of confocal $z$-stacks $(0.3 \mu \mathrm{m})$ without postprocessing, and spines were defined visually and counted manually. Spine density is expressed as the number of spines per $10 \mu \mathrm{m}$ length of dendrite. Spine maturation index is defined as the ratio of mushroom spines to all other spine types, with mushroom spines defined by the spine head at least twice as wide as the spine neck (Fig. $2 \mathrm{~A}$, right). Spine length was measured from the base of the spine at the dendritic shaft to the top, or head for mushroom spines (ImageJ software). Statistical analysis was by ANOVA followed by Dunnett post hoc analysis (SPSS software). The error bars in all graphs represent SEM, and statistically significant differences are indicated $\left({ }^{\star} p<0.05,{ }^{* *} p<0.01\right)$.

Immunohistochemistry. Mouse brain was dissected rapidly after transcardiac perfusion with ice-cold saline under deep anesthesia. Hemispheres were fixed overnight at $4^{\circ} \mathrm{C}$ in either $4 \%$ paraformaldehyde (PFA) or in fixative according to Bouin: $71.4 \%$ saturated picric acid, $23.8 \%$ formaldehyde, $4.8 \%$ glacial acidic acid. Sagittal vibratome sections $(40 \mu \mathrm{m})$ were stored in PBS with $0.1 \%$ sodium azide before analysis by IHC performed as described previously (Terwel et al., 2005). After blocking with $10 \%$ fetal calf serum, sections were incubated overnight at $4^{\circ} \mathrm{C}$ with primary antibody: Tau5 (PharMingen) and Tau1 (Roche) for total Tau, HT7 for human Tau, and AT8 and AT180 (Thermo Scientific) for phospho-Tau. Secondary antibodies were goat anti-mouse or goat antirabbit IgG, labeled with horseradish peroxidase or biotin (DAKO).

Phosphatase antigen retrieval. Sagittal sections were incubated with calf intestinal alkaline phosphatase (CIAP) (New England Biolabs) at 600 $\mathrm{U} / \mathrm{ml}$ in $100 \mathrm{~mm}$ Tris- $\mathrm{HCl}, \mathrm{pH} 8.0$, for $5 \mathrm{~h}$ at $37^{\circ} \mathrm{C}$. After phosphatase activity was quenched by incubation in $50 \mathrm{~mm}$ Tris- $\mathrm{HCl}, \mathrm{pH} 7.6,0.2 \mathrm{M}$ $\mathrm{NaCl}$ at $0^{\circ} \mathrm{C}$, immunohistochemistry was performed as above.

Biochemical analysis by Western blotting. Total forebrain or cortex was homogenized as described previously (Terwel et al., 2005, 2008) and proteins separated on $10 \%$ Tris-glycine SDS-PAGE gels (Anamed). After protein transfer, nitrocellulose membranes were probed with primary antibodies: Tau 5 and HT7 for total Tau; and AT8, AT180, AD2, and pS199 for phosphorylated Tau.
Hippocampal synaptosomes were prepared as described previously (Pérez-Otaño et al., 2006) from total hippocampal homogenates after centrifugation for $15 \mathrm{~min}$ at $1000 \times g$ at $4^{\circ} \mathrm{C}$. The supernatant was centrifuged again for $15 \mathrm{~min}$ at $10,000 \times g$ at $4^{\circ} \mathrm{C}$ to obtain a crude synaptosomal pellet. The pellet was resuspended in 10 volumes of homogenization buffer (0.32 $\mathrm{m}$ sucrose, 4 mM HEPES, $\mathrm{pH} 7.4)$ and pelleted again to yield the washed synaptosomal pellet, which was resuspended for analysis on Western blot as described above.

Primary hippocampal neurons and immunocytochemistry. Primary cultures of hippocampal neurons were prepared from wild-type Friend virus B-type (FvB) mouse embryos (E16-E18) according standard procedures (Banker and Cowan, 1977; Dotti et al., 1987). Neurons were seeded on poly-L-lysine-coated glass coverslips (150,000 cells per $60 \mathrm{~mm}$ dish). They were cultured for up to $16 \mathrm{~d}$ in Neurobasal medium with B-27 supplement (Invitrogen) in the presence of an astroglial feeder layer. At the indicated time points, cells were fixed with $4 \%$ paraformaldehyde for $10 \mathrm{~min}$ and subsequently washed and stored in PBS until analysis.

Immunocytochemistry was performed on cultured neurons on single coverslips by incubating with PBS containing $0.1 \%$ Triton X-100 (PBST) before blocking of nonspecific binding sites by incubation with $1 \%$ fetal calf serum in PBST (PBST/FCS). Coverslips were incubated with primary antibodies as indicated: Tau5 (PharMingen) and Tau1 (Roche) for total Tau; AT8 and AT180 (Thermo Scientific) for phosphorylated Tau; MAP2 (Sigma) as dendritic marker; SV2 (Abcam) as presynaptic marker; and PSD95 (Abcam) as postsynaptic marker. All antibodies were suitably diluted in PBST/FCS for $3 \mathrm{~h}$ at room temperature. Neurons were washed in PBST and incubated for $1 \mathrm{~h}$ at RT with secondary antibodies labeled with either streptavidin, Alexa488, or Alexa594 (Invitrogen), as indicated. Eventually coverslips were additionally incubated with phalloidin labeled with Alexa488 (Invitrogen) as indicated to reveal fibrillar actin. Coverslips were washed in PBS and mounted in Mowiol 1,4diazabicyclo[2.2.2] octane mounting media for standard and confocal fluorescence microscopy.

\section{Results}

\section{Time line of defects in Tau.P301L mice}

Since the generation and initial characterization of our Tau.P301L mouse model for tauopathy (Terwel et al., 2005), we continued to collect data on cognitive and general behavior, and we analyzed clinical, biochemical, histological, and pathological parameters, including the premature death from our breeding colony. The accumulated comprehensive dataset allows a reliable time line of characteristics and defects, including a precise Kaplan-Meier mortality curve (Fig. 1). The mortality was recently demonstrated to be closely associated with upper airway defects originating in the brainstem and leading to physical exhaustion and asphyxia of the Tau.P301L mice around age 9-10 months (Dutschmann et al., 2010; Menuet et al., 2011). No gender differences have been noted for mortality nor for any other characteristic of the Tau.P301L mice (Terwel et al., 2005, 2008; Boekhoorn et al., 2006; Dutschmann et al., 2010; Menuet et al., 2011; this study).

The surprising finding of improved cognition and LTP at young age (Boekhoorn et al., 2006), in sharp contrast to the later cognitive dysfunction and pathology (Terwel et al., 2005), remains to be explained. Here, we concentrate on the characteristics of dendritic spines in Tau.P301L mice at two early, clinically presymptomatic stages.

\section{Analysis of dendritic spines}

We analyzed dendritic spines in brains of Tau.P301L mice as part of a comprehensive study of the mouse models we developed, characterized, and validated over the last decade (Moechars et al., 1999; Spittaels et al., 1999, 2000; Terwel et al., 2005, 2008; Boekhoorn et al., 2006; Dutschmann et al., 2010). Here we report on 


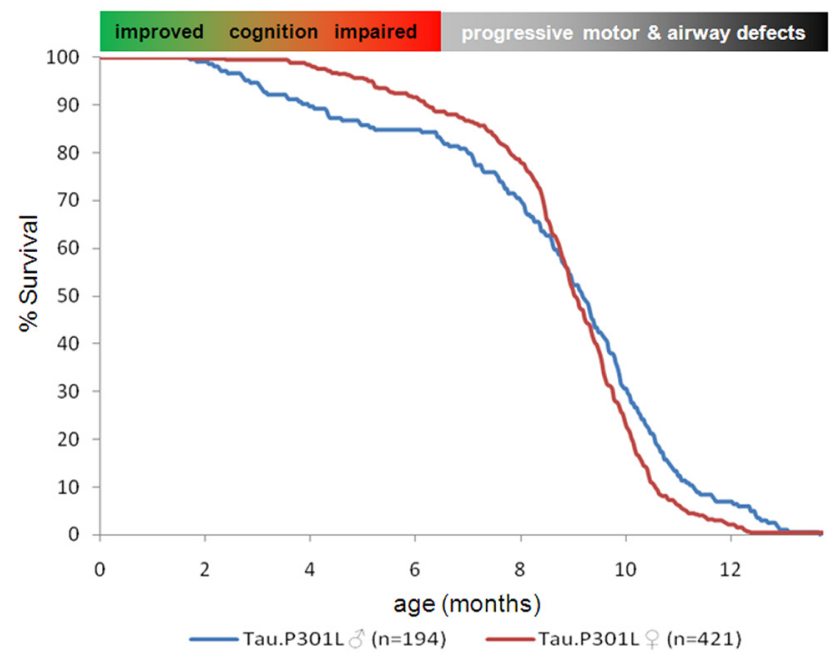

Figure 1. Premature mortality of Tau.P301L mice. The premature death rate is illustrated by the Kaplan-Meier curve based on 421 female and 194 male Tau.P301L mice. The mean age of survival is 9.4 months, without a gender difference, and with practically no survivors over age 12 months. Indicated by the horizontal boxes are the approximate time windows of improved and defective cognition in young and adult Tau.P301L mice, respectively. The progressive motor problems of aging Tau.P301L mice result in severe defects in the terminal phase, defined by decreasing weight, abnormal posture, and ultimately the upper airway defects as the likely cause of death (Dutschmann et al., 2010; Menuet et al., 2011).

Tau.P301L and Tau.4R mice, while analyses of APP.V717, GSK $3 \beta$, biAT, and biGT mice are in progress.

All genotypes were crossed with transgenic YFP mice to generate double and triple transgenic mice expressing the transgenic human proteins in fluorescently marked neurons, processes, and spines (Fig. 2A). The thy1-YFP strain was selected because of the neuron-specific expression of relatively low levels of YFP (Feng et al., 2000). Moreover, the same mouse thyl gene promoter was used as in all our transgenic mice. Confocal microscopy additionally demonstrated that transgenic YFP and Tau.P301L were coexpressed in neurons in the analyzed brain regions (boxed in Fig. $2 A$ ). The overall strategy allowed us to analyze dendritic spines in great detail in specified brain regions of all genotypes at different ages, as outlined in the introductory section. The measured parameters of spines are relevant for synaptic plasticity and cognition: spine density per unit dendrite length, relative spine length, and spine maturation index. The index, defined as the ratio of the number of mushroom spines to the number of other spine types, is based on the understanding that mushroom spines carry mature and functional synapses (Hering and Sheng, 2001). The brain regions were selected in the hippocampus and cortex (Fig. $2 \mathrm{~A}$ ) because these are informative for many tauopathies, including frontotemporal dementia (FTD) and AD.

\section{Dendritic spines in young and adult Tau.P301L mice}

Spines in Tau.P301L mice were analyzed at young and adult ages. The spines of young mice were analyzed at 1-2 months to correlate with their improved cognition. The spines of adult mice were analyzed at 4-6 months to correlate with their defective cognition (Terwel et al., 2005, 2008; Boekhoorn et al., 2006). The analysis yielded quantitative datasets (Fig. $2 B, C$ ) with the most salient aspects schematically summarized in Table 1.

In the cortex and hippocampus of young Tau.P301L mice, the spine density was not significantly different from that in young control YFP mice at the same age of 1-2 months (Fig. 2B, Table 1). However, the maturation index of spines was significantly higher in the hippocampus and cortex of young Tau.P301L mice. Moreover, mushroom spines were longer in the cortex of young Tau.P301L mice than in control mice (Fig. 2 B, right; Table 1). In the hippocampus of young Tau.P301L mice, only the maturation index was affected, with a significant increase in the stratum oriens (Table 1).

In the hippocampus of adult Tau.P301L mice (4-6 months), spine density was not affected, while the spine maturation index remained significantly higher than in control mice. The most marked contrast with young Tau.P301L mice was the overall length of mushroom spines, which was significantly reduced relative to the length of such spines in control mice (Fig. 2C, Table 1). Therefore, the length of mushroom spines correlates with the defective cognition of adult Tau.P301L mice.

In the cortex of adult Tau.P301L mice, the spine maturation index and length of mushroom spines were both reduced to control levels from the initially higher levels in young Tau.P301L mice (Fig. $2 B, C$, Table 1). Conversely, the spine density increased significantly in adult Tau.P301L mice, which can be explained by significantly more short stubby and thin spines (Fig. $2 B, C$, Table 1; data not shown).

The combined data demonstrate that, compared to spine density, maturation index and length of mushroom spines more closely correlate with improved cognition in young mice and with defective cognition in adult mice of this model for Tau pathology.

\section{Dendritic spines in adult Tau.4R mice}

Tau.4R transgenic mice express wild-type human Tau.4R to the same level as Tau.P301L mice, driven by the same mouse thy1gene promoter, and in the same genetic background (Spittaels et al., 1999; Terwel et al., 2005; Sennvik et al., 2007). Here, only adult Tau.4R mice (4-6 months) were analyzed for spines because analysis of cognition is not possible, hampered by the motoric problems caused by the axonopathy (Spittaels et al., 1999).

The analysis of spines revealed similar effects in adult Tau. $4 \mathrm{R}$ mice as in adult Tau.P301L mice. The spine density was significantly higher in the cortex and hippocampus of adult Tau.4R mice (Fig. 2C, Table 1). On the other hand, the length of mature spines was significantly shorter not only in the hippocampus but also in the cortex of Tau.4R mice (Fig. 2C, Table 1). Unchanged, but thereby notably conspicuous, was the maturation index of dendritic spines in Tau.4R mice (Fig. 2B, C, Table 1). This observation was surmised to directly relate to the typical axonopathy of the Tau.4R mice (Spittaels et al., 1999), which was confirmed by subsequent analysis (vide infra).

The important issues raised by previous studies and revived by the analysis of spines were further approached by biochemical analysis of brain and synaptosomes, by analysis of primary neurons, and by rigorous immunohistochemical analysis of mouse brain sections.

\section{Synaptosomes contain mouse and human protein Tau}

Biochemically, in total forebrain protein extracts, no major differences were evident in either the total level of protein Tau or in its phosphorylation in young and adult Tau.P301L mice (Fig. $3 A$ ). Obviously, the differences in cognition and in dendritic spine morphology between young and adult Tau.P301L mice are not explained simply by overall levels or by marked differences in phosphorylation of protein Tau.

Isolated synaptosomes from mouse hippocampus were analyzed biochemically for markers that eventually would correlate and explain the changes in spine morphology and cognition. The 

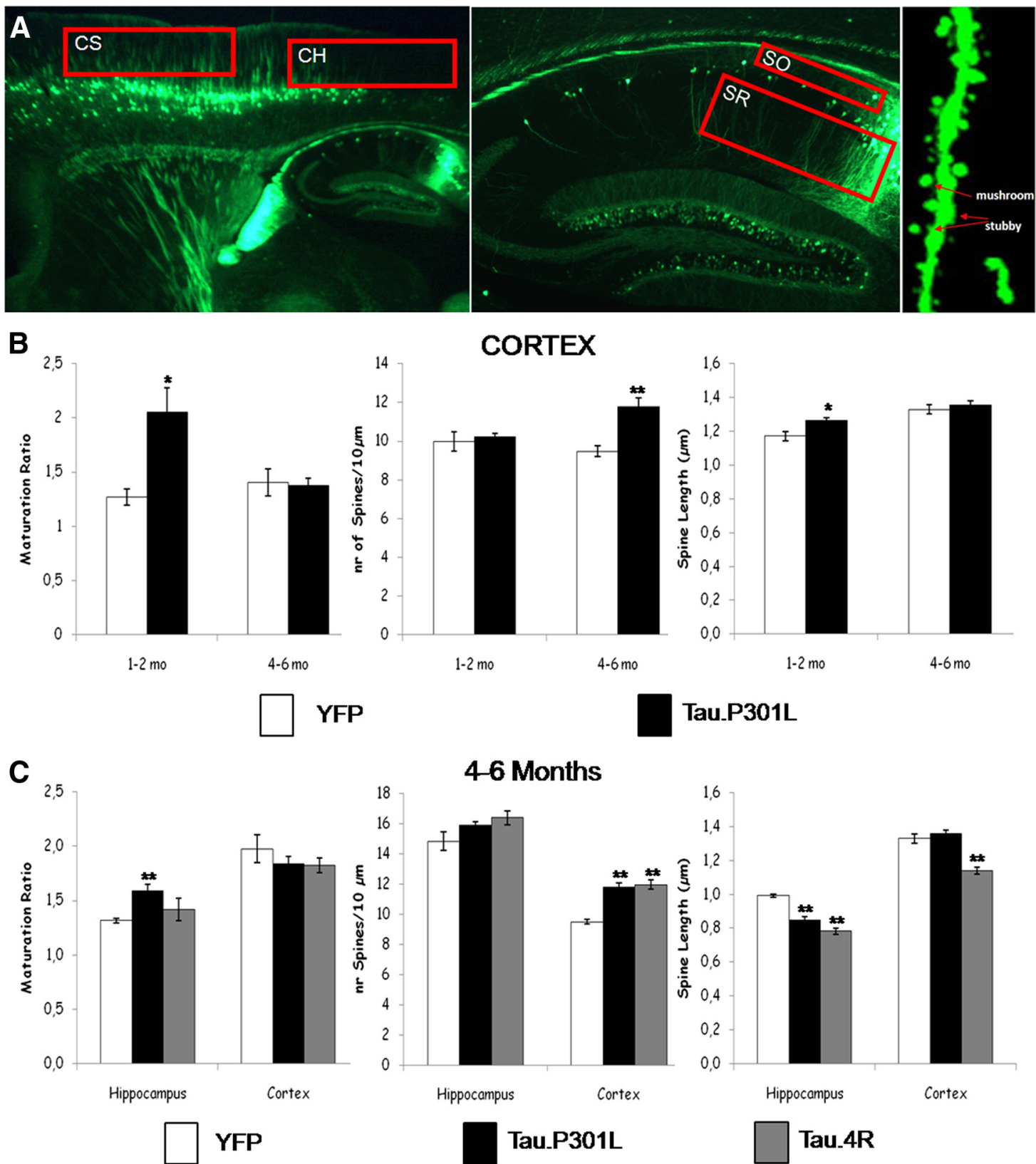

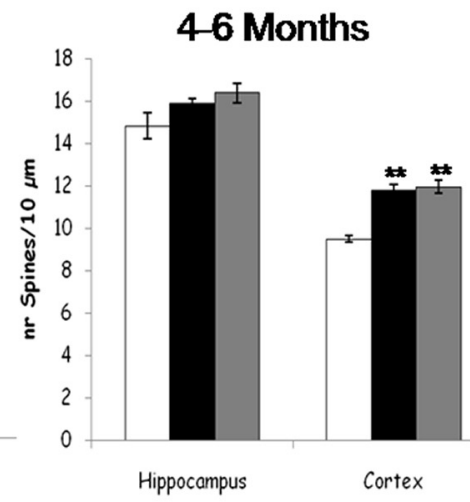

Tau.P301L

\section{Tau.P301L}

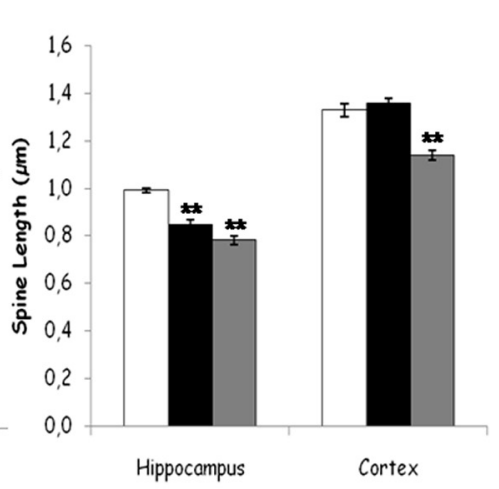

Tau_4R

Figure 2. Dendritic spines in different brain regions of Tau.P301L mice. A, Pyramidal neurons in four specified regions of hippocampus and cortex of Tau.P301L mice crossed to YFP mice: S0, SR, and layer III neurons in CH and CS. Left, Enlarged image of dendritic spines. B, Parameters of spines in cortex of young and adult Tau.P301L mice crossed to YFP mice (black bars) relative to wild-type YFP mice (open bars). Graph of spine maturation index shows ratio of mushroom spines to other types of spines (left). Spine density is represented as number of spines per $10 \mu \mathrm{m}$ dendritic shaft (middle). Spine length was measured in micrometers (right). The data are values measured in the cortical region denoted CS in $A$. C, Parameters of spines in hippocampus and cortex of adult Tau.P301L (black bars) and Tau.4R mice (gray bars) both crossed to YFP mice, and compared to wild-type YFP mice (open bars). The data are values measured in the cortical region denoted (S and hippocampal region SR in $A$. All error bars represent SEM, with statistical significance denoted by asterisk $\left({ }^{*} p<0.05 ;{ }^{* *} p<0.01\right)$.

Table 1. Modulation of spine parameters by Tau.P301L and Tau0.4R expression

\begin{tabular}{|c|c|c|c|c|c|c|c|c|c|c|c|c|c|}
\hline \multirow[b]{3}{*}{ Genotype } & \multirow[b]{3}{*}{ Age } & \multicolumn{4}{|c|}{ Density } & \multicolumn{4}{|c|}{ Maturation index } & \multicolumn{4}{|c|}{ Mushroom length } \\
\hline & & \multicolumn{2}{|c|}{ CA1 } & \multicolumn{2}{|l|}{ Cortex } & \multicolumn{2}{|l|}{ CA1 } & \multicolumn{2}{|c|}{ Cortex } & \multicolumn{2}{|l|}{ CA1 } & \multicolumn{2}{|l|}{ Cortex } \\
\hline & & SR & so & CS & $\mathrm{CH}$ & $S R$ & So & CS & $\mathrm{CH}$ & $S R$ & so & CS & $\mathrm{CH}$ \\
\hline \multirow{2}{*}{ P301L } & $4-6 \mathrm{mo}$ & & & $\uparrow^{* *}$ & $\uparrow^{* *}$ & $\uparrow^{* *}$ & $\uparrow^{*}$ & & & $\downarrow$ ** & $\downarrow * *$ & & \\
\hline & $4-6 \mathrm{mo}$ & & $\uparrow *$ & $\uparrow * *$ & $\uparrow^{*}$ & & & & & $\downarrow * *$ & $\downarrow$ ** & $\downarrow$ ** & $\downarrow *$ \\
\hline
\end{tabular}


A

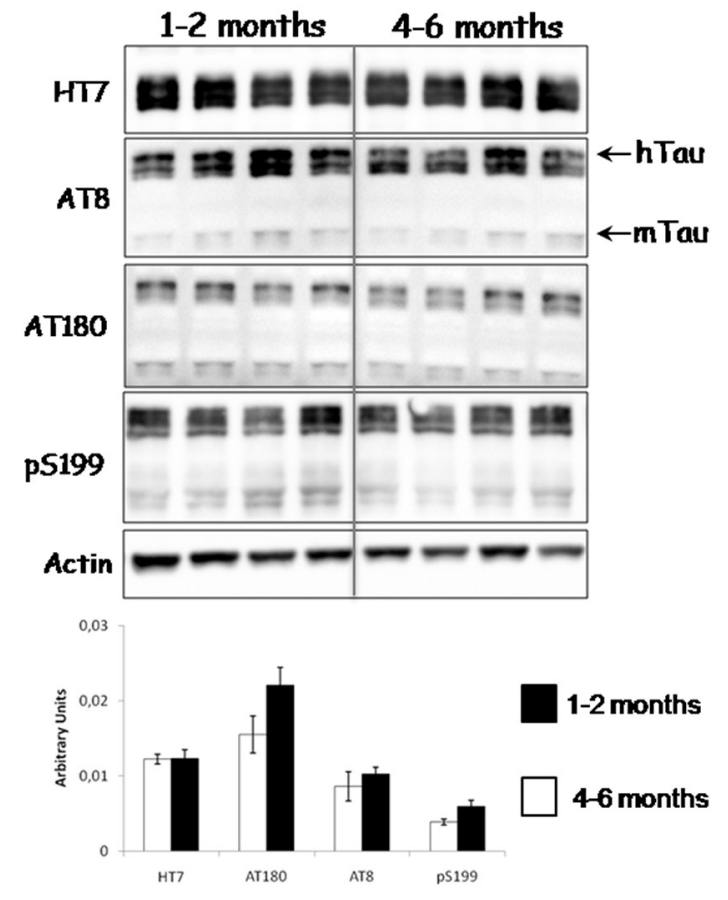

C

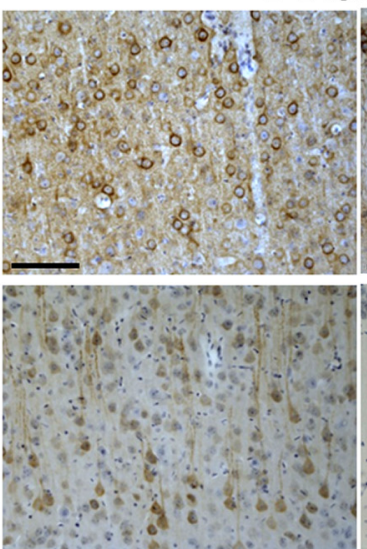

1-2 months
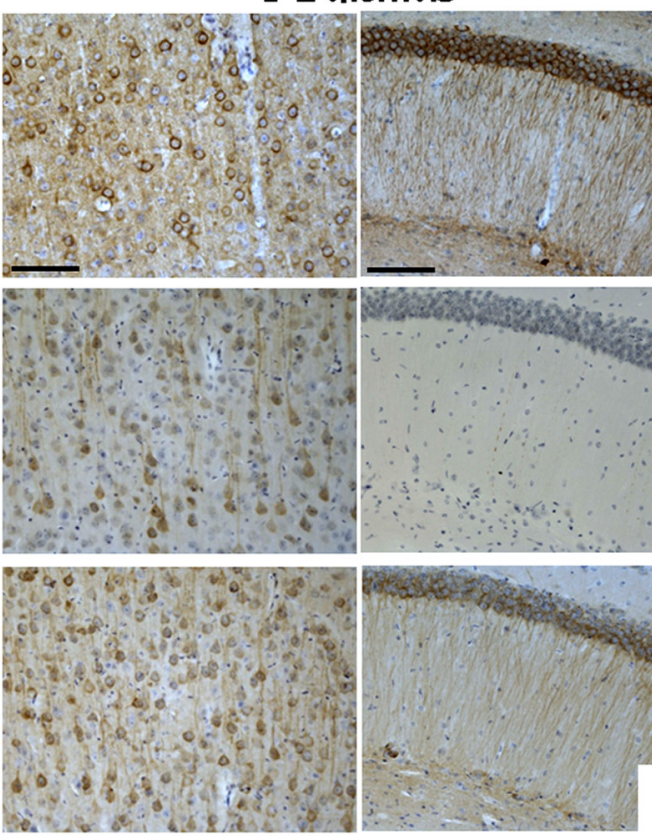

B
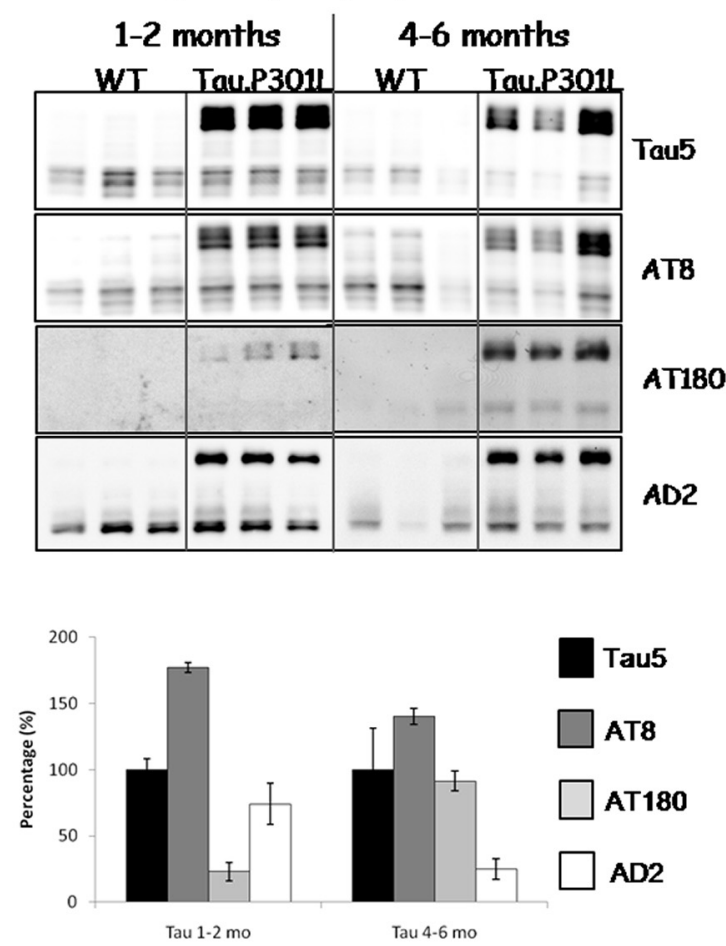

4-6 months
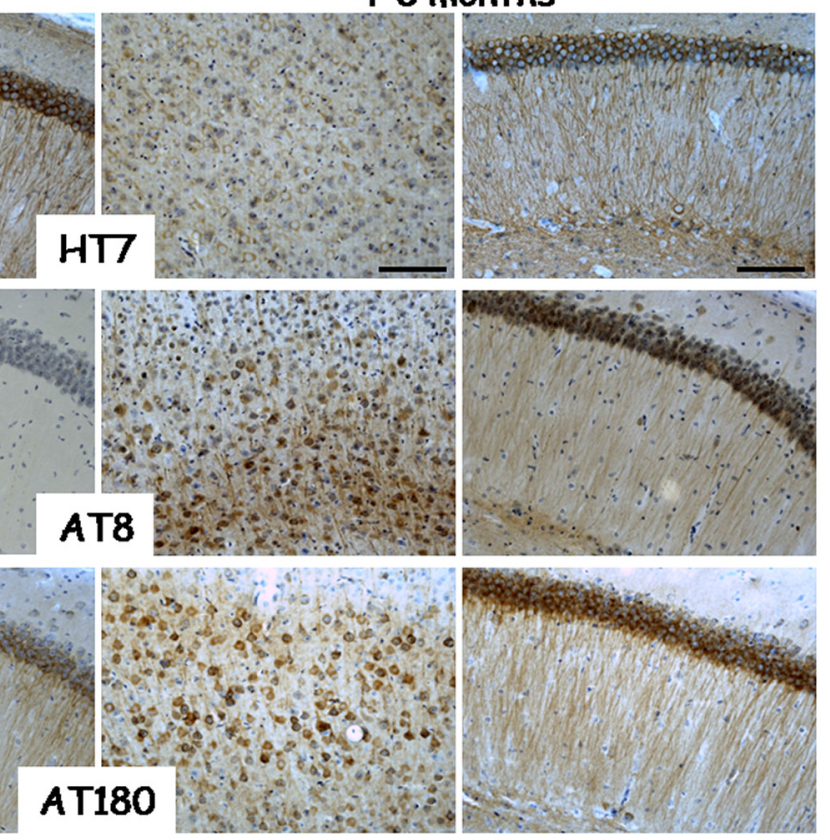

Figure 3. Phosphorylation of Tau in brain of young and adult presymptomatic Tau.P301L mice. A, Representative Western blots for total human Tau (HT7) and for phosphorylated epitopes AT8, AT180, and pS199 on human and mouse Tau (denoted by hTau and mTau, respectively, in top panel). The blots were recorded and quantified digitally (bottom) ( $n=6$ per age group). Error bars represent SEM. B, Hippocampal synaptosomes isolated from nontransgenic mice and from Tau.P301L mice contained human and mouse protein Tau, as well as variable amounts of phosphorylated isoforms detected by the specific antibodies indicated. Representative blots are shown, recorded, and quantified digitally (bottom) ( $n=7$ per genotype). Error bars represent SEM. $C$, IHC for human Tau in young and adult presymptomatic Tau.P301L mice. Top, Total human Tau (HT7). Middle, AT8 (pS199/S202/S205). Bottom, AT180 (pT231/S235). Scale bars, 100 $\mu \mathrm{m}$.

experimental outcome was, however, negative. For one, synaptosomes from Tau.P301L and wild-type mice contained similar levels of glutamate receptors NMDA-R and GluR1 (data not shown). Similarly, several presynaptic or postsynaptic proteins were evaluated in different preparations of synaptosomes, some further purified by Percoll gradient centrifugation. Attempts failed to reveal a consistent pattern of markers that could explain the observations on spines and cognition described here and previously (Terwel et al., 2005, 2008; Boekhoorn et al., 2006; Sennvik et al., 2007).

The most consistent finding was nevertheless interesting: human transgenic Tau.P301L as well as endogenous mouse Tau were present in synaptosomal preparations isolated from 
Tau.P301L mice (Fig. 3B). In addition, well known phosphorylated isoforms of protein Tau, similar to those found in total brain extracts, were biochemically detected in synaptosomes (Fig. $3 A, B)$. Nevertheless, a notable difference between biochemical and immunohistochemical analysis of the same brains became evident.

\section{Immunohistochemistry with AT8 and AT180 for phosphorylated protein Tau}

By our standard method of immunohistochemistry, we observed in adult Tau.P301L mice the mutant protein in somata of pyramidal neurons in cortex and hippocampus, and in proximal and distal segments of apical dendrites (Fig. $3 C$, right), thus extending our previous observations (Terwel et al., 2005; Boekhoorn et al., 2006; Sennvik et al., 2007).

In the brain of young Tau.P301L mice, the phosphorylation of mutant Tau detected with AT8 was weaker, albeit with regional differences: minimal in hippocampus while more distinct throughout cortical layers (Fig. 3C, left). Somewhat unexpectedly, reaction with AT180 (pT231/pS235) was the earlier and prominent phosphorylated Tau marker (Fig. 3C, left). Reaction with AT180 remained important in hippocampal and cortical pyramidal neurons in brains of adult Tau.P301L mice, both in somata and segments of apical dendrites (Fig. $3 C$, right).

AT8 is the marker of choice in pathological settings to define pretangle and tangle pathology in human brain (Braak and Braak, 1991). Nevertheless, though the reaction with AT8 was weak in the brain of young Tau.P301L mice, its mere presence early in life extends its dual or even ambiguous designation as a fetal and pathological epitope. Of note, the early presence of AT8 is consistent with the most recent findings of AT8 in the brain of children (Braak and Del Tredici, 2011).

In the brain of adult Tau.P301L mice, the intensity of reaction in the hippocampus increased markedly for AT180, but was even more forceful for AT8, which distinctly marked CA1 soma and dendrites, comparable to AT180 and total human Tau (HT7) (Fig. 3C, right).

Comparing the immunohistochemical and biochemical data obtained with AT8 revealed an apparent contradiction, already referred to in the previous section. The biochemical levels of AT8 in total brain extracts of young mice was inconsistent with the weak reaction in immunohistochemistry. More AT8-positive protein Tau was evident in the somata of CA1 pyramidal neurons in adult Tau.P301L mice (Fig. 3C, right). We ascribe this to augmented phosphorylation and also to relocalization into somata of phosphorylated protein Tau, which carries the AT8 epitope.

\section{Protein Tau in primary neurons}

Because of the marked effects of protein Tau on spinogenesis and on the subsequent pathological evolution of spines in mouse brain, we aimed to visualize its localization more precisely, eventually in dendrites and spines. We analyzed primary cultures of hippocampal neurons generated from wild-type mouse embryos (E16-E17), in which protein Tau is accepted as axonal microtubule-associated protein (MAP) and even as an axonal marker, especially in the absence of more reliable axonal markers (Dotti et al., 1987; Papasozomenos and Binder, 1987). MAP2 is the accepted marker for dendrites in primary cultures because it is excluded from axons. MAP2 is therefore also used as a negative, exclusion marker for axons.

Surprisingly, mouse protein Tau was evident in most processes of wild-type primary neurons, colocalizing with MAP2 even though the reaction for protein Tau was weaker (Fig. $4 A, B$ ).
Moreover, the localization of both MAPs differed importantly: in axons, protein Tau was present equally throughout the volume of axons, while in dendrites, protein Tau was restricted to a patchy distribution along the membranes (Fig. 4A,B).

Of note, murine protein Tau was evident in dendritic protrusions on primary neurons, particularly when stained for total Tau, although these presumed spines were not nearly as distinct or demarcated as in brain sections from YFP mice and the combinations and Tau did not colocalize with F-actin (Fig. 4A, compare to Fig. 2A). Moreover, protein Tau colocalized with the presynaptic marker SV2 but only very partially with the postsynaptic marker PSD95 (Fig. 4C).

Immunocytochemistry for phospho-epitopes AT8 and AT180 revealed different aspects: smooth throughout the cytoplasm for AT8 and granular for AT180 (Fig. 4A). Moreover, in contrast to staining for total protein Tau and for AT8, reaction with AT180 was largely restricted to the soma and dendritic shafts, while almost completely excluded from the dendritic protrusions (Fig. $4 B$ ).

In parallel experiments, primary mouse neurons were transduced with adeno-associated viral vectors (AAVs) to express either human wild-type Tau.4R or mutant Tau.P301L (Jaworski et al., 2009b). After 5 d, protein Tau became localized in the cytoplasm throughout soma, axons, and dendrites, including spines (data not shown). No marked differences in localization were noted between human wild-type and mutant Tau. Again, reactions for AT8 and AT180 were evident in only a subset of spines (data not shown).

Because in wild-type primary neurons, the localization of protein Tau rather confirmed the classic view of an axonal MAP, and because even in transfected primary neurons the analysis was not conclusive for the presence of protein Tau in dendritic spines, further immunohistochemical analysis was more extensive.

\section{Mouse protein Tau is lacking from dendritic spines in mouse brain}

Our standard procedure for IHC on free-floating sagittal or coronal brain sections failed to distinctly reveal the presence of human Tau in dendritic spines of the transgenic mice (Figs. 3, 4). In contrast to localization of transgenic human Tau, the localization of endogenous mouse Tau in brain sections proved most challenging and obliged us to invest in different methods of fixation, embedding, sectioning, antigen retrieval, and antibodies, described here only briefly and in part.

First, because even in normal physiological conditions phosphorylation of protein Tau is variable in extent and positions, we pretreated brain sections with alkaline phosphatase for detection of nonphosphorylated Tau with Taul (specific for S199/S202) (Papasozomenos and Binder, 1987). Detection of endogenous and human transgenic Tau was thereby improved, but dendritic spines remained unmarked for endogenous murine and human mutant protein Tau (Fig. 5A; data not shown).

To better preserve the cytoskeleton (Trojanowski et al., 1989), we next applied fixation according to Bouin by perfusion and/or by postfixation. This resulted in improved visualization of actin filaments, the main cytoskeletal elements in spines (Fig. $5 B$; data not shown). Nevertheless, mouse protein Tau was detected in CA1 stratum radiatum of wild-type mice merely as discrete puncta surrounding empty neuronal processes (Fig. 5B). These represent presynaptic compartments of Schaffer collaterals docking onto proximal segments of the dendrites from CA1 neurons (Binder et al., 1985). Consequently, our data verify the axonal and presynaptic localization of mouse Tau (Dotti et al., 1987; 
A
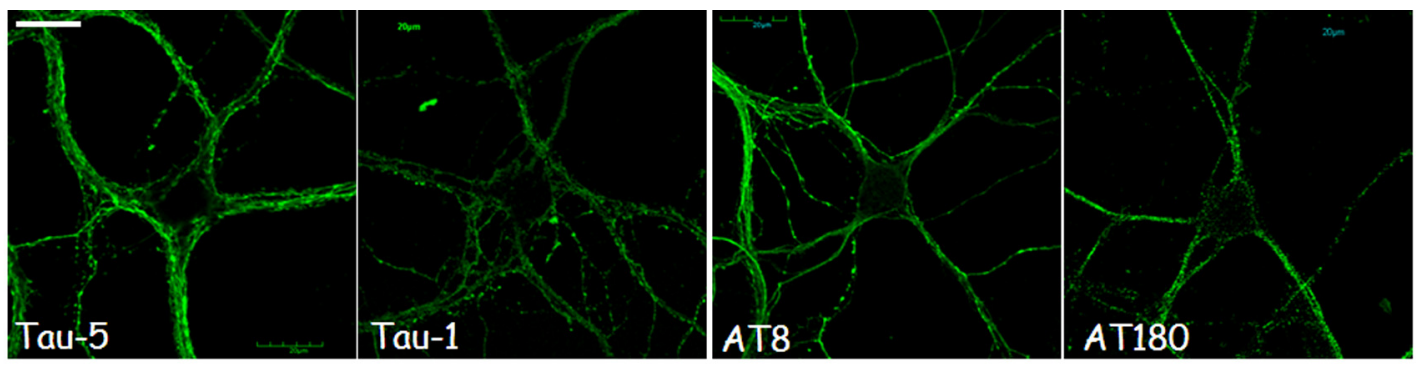

B
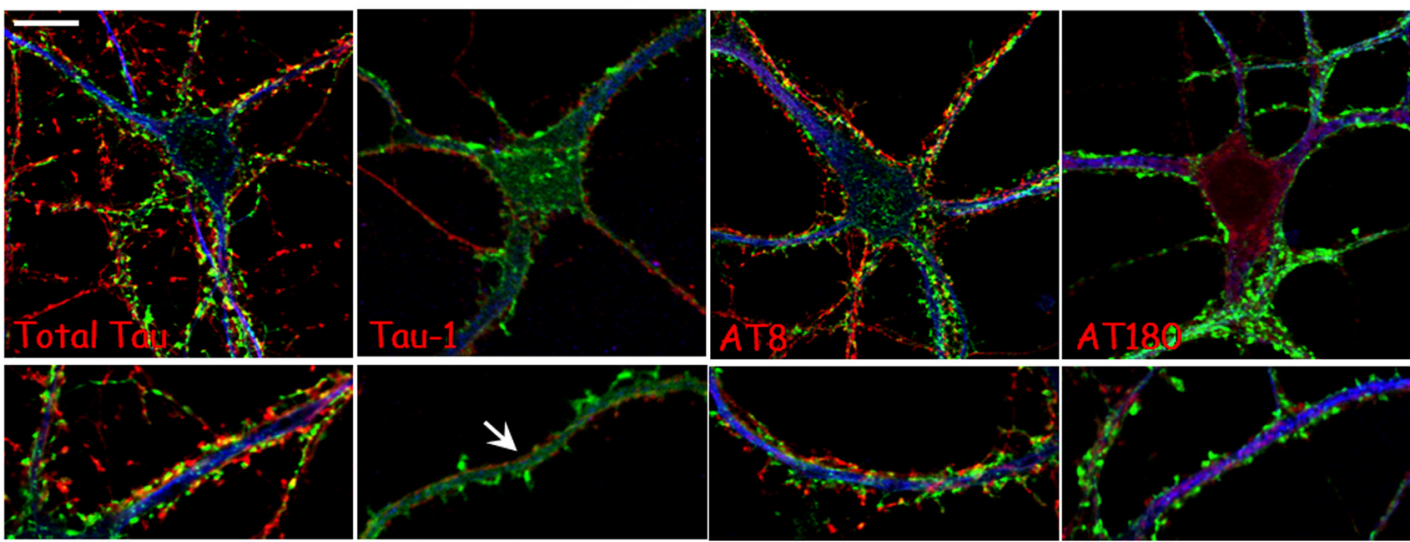

Tau

Phalloidin

C

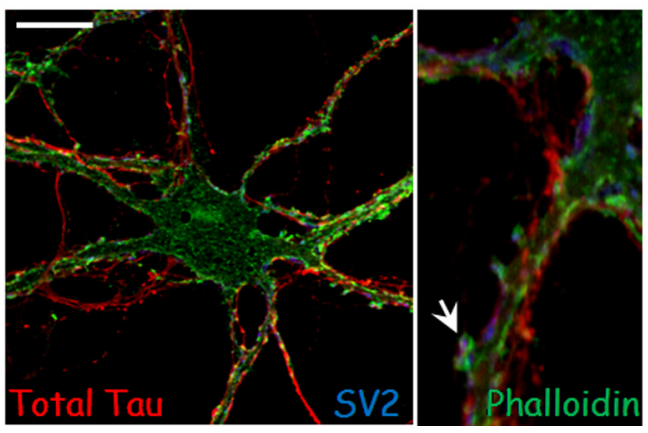

MAP2
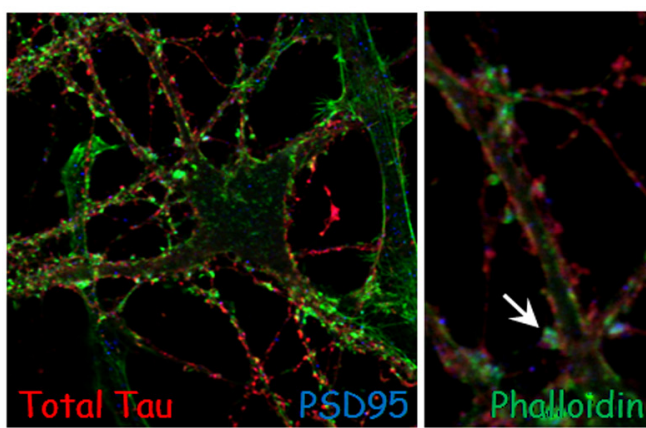

Figure 4. Localization of endogenous mouse protein Tau in primary neurons. A, Primary hippocampal neurons of 16 DIV express mouse Tau (left) and phosphorylated mouse Tau (right) in cytoplasm of cell body and processes. B, Colocalization of mouse protein Tau (red) with MAP2 (blue) and F-actin (green). Note total Tau and particularly Tau-1 (arrow) and AT8 on dendritic membranes and in spines, while AT180 colocalized with MAP2 (right). C, Total mouse protein Tau (red) colocalized with F-actin (green) and with presynaptic markers SV2 (left) and postsynaptic marker PSD95 (right) (both blue) in spinelike protrusions (arrows). Scale bars, $20 \mu \mathrm{m}$.

Papasozomenos and Binder, 1987), but the data do not document the presence of mouse protein Tau in dendritic spines.

\section{Mutation and phosphorylation defines localization of human protein Tau}

The additional steps in IHC analysis, although negative for mouse Tau in spines, did yield extra information on the localization of human protein Tau in the brain of transgenic Tau.P301L and Tau4R mice.

IHC for human protein Tau was more intense in brain sections fixed according to Bouin, although the overall distribution of total Tau (HT7) was similar to that of standard fixed sections (Fig. 5C, compare to Fig. 2A, panels labeled HT7). Conversely, IHC with AT8 remained weak on sections fixed according to Bouin, relative to total Tau and AT180, but AT8 revealed the most striking difference between Tau.P301L and Tau.4R mice (Fig. 5C, middle). This was unexpected because AT8 is the generally accepted "pretangle" marker, while Tau.4R mice, unlike Tau.P301L mice, do not suffer tauopathy defined by fibrillar Tau aggregates (Spittaels et al., 1999; Terwel et al., 2005).
Interestingly, marked differences for total human Tau and the AT8 and AT180 epitopes were most evident in the CA3 subregion, where localization of Tau.4R and Tau.P301L were markedly different. In Tau.4R mice, the CA3 stratum lucidum contained almost no protein Tau (Fig. 5C), while Tau.P301L localized in dendrites in the stratum lucidum and stratum lacunosum moleculare of CA3 (Fig. $5 C$ ). Reaction with AT8 was weak in CA3 of Tau.P301L mice, in contrast to strong reaction in all CA3 strata except stratum lucidum of Tau.4R mice (Fig. 5C). Finally, AT180 also marked the CA3 region of Tau.4R mice more intensely than in Tau.P301L mice, including the cell bodies in the stratum pyramidale (Fig. $5 C$ ).

The CA1 hippocampus subregion was inspected in greater detail and at higher magnification (Fig. 6). Phosphorylated Tau.P301L was evident in dendrites and spines in CA1 (Fig. $6 A, B$, red arrows) as well as in other structures (Fig. 6A, lower left). In contrast, phosphorylated Tau.4R was contained in axons in the neuropil (Fig. 6C), corroborating the axonopathy of Tau.4R mice (Spittaels et al., 1999; Künzi et al., 2002). Interestingly, reaction with AT180 was confined to dendrites of CA1 stratum radiatum in both Tau.P301L and Tau.4R mice (Fig. 6C), 
A

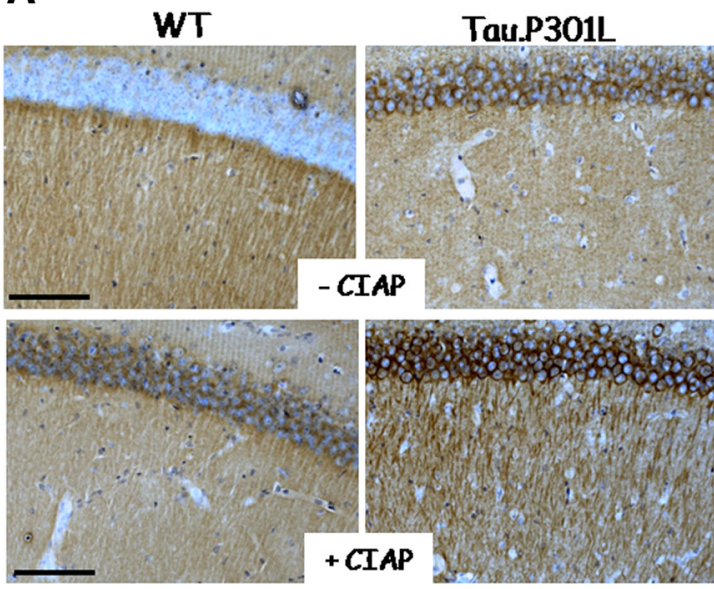

B
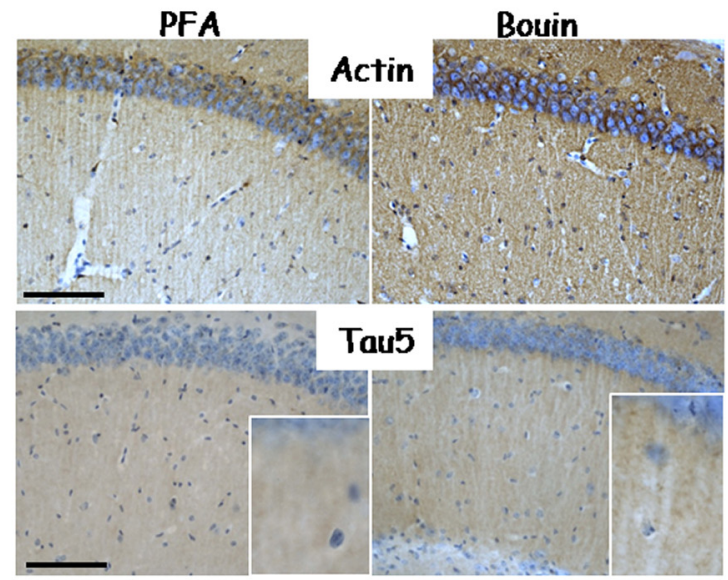

C

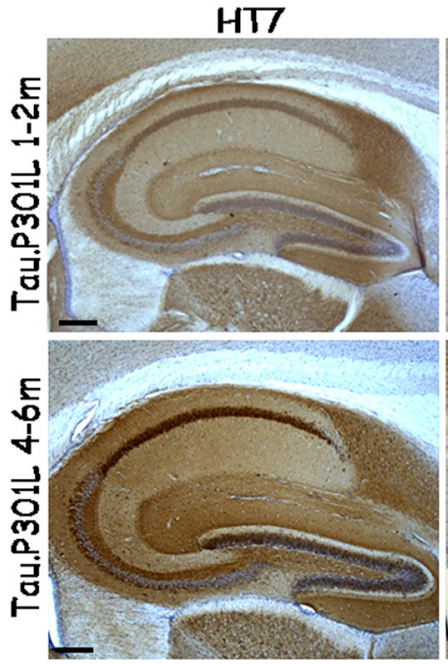

\section{Bouin}

AT8

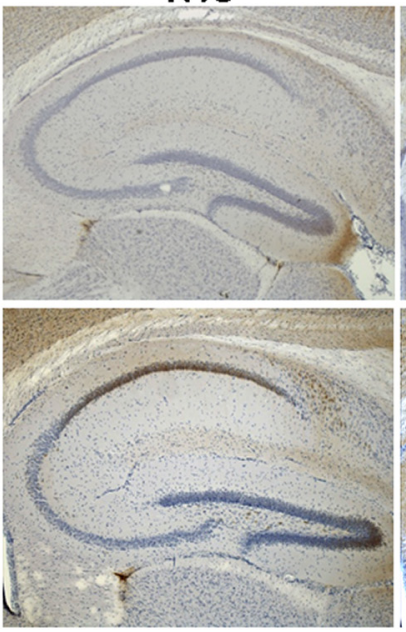

AT180

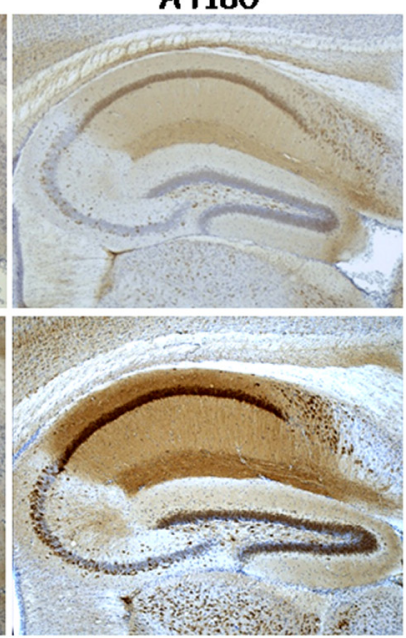

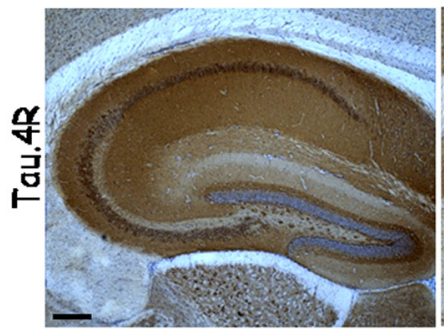
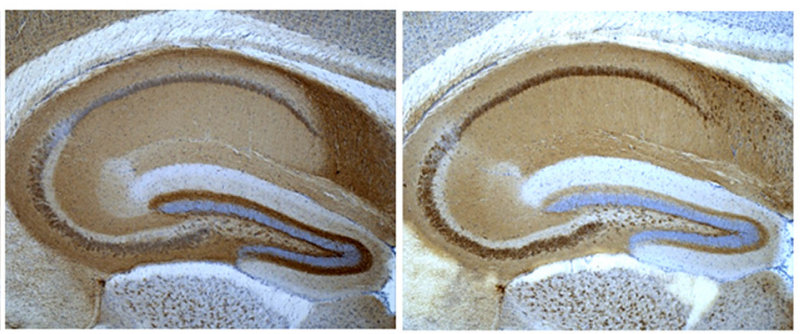

Figure 5. Alkaline phosphatase and fixation according to Bouin improves IHC for protein Tau. A, Brain sections were incubated with CIAP as indicated (WT mice, left; Tau.P301L mice, right) and immunostained with Tau1 for unphosphorylated mouse and human protein Tau, respectively. Note the markedly denser reaction, particularly for endogenous mouse Tau in the CA1 somata. Scale bar, $100 \mu \mathrm{m}$. B, Fixation according to Bouin of brain sections from wild-type mice stained for $\beta$-actin improves reaction of cytoskeletal elements compared to PFA fixation. Scale bars, $100 \mu \mathrm{m}$. $C$, Fixation according to Bouin improved detection of protein Tau.P301L, while distribution of human Tau (HT7) and pTau (AT8, AT180) in hippocampus of Tau.P301L mice was unchanged (top, compare to Fig. 2A). When compared to Tau.4R mice (bottom), the stronger reaction with AT8 in hippocampus of Tau.4R mice is evident. Scale bar, $200 \mu \mathrm{m}$.

while only a subset of spines reacted and only in the CA1 stratum radium of Tau.P301L mice (Fig. $6 A, B$ ).

In the cortex of both strains of Tau mice, dendrites were burdened with phospho-Tau carrying both AT8 and AT180 epitopes (Fig. 6A-C). Phospho-Tau was, however, barely detectable with AT8 in spines in the cortex of Tau.P301L mice, while readily evident in cortical spines in Tau.4R mice (Fig. 6C). In contrast, AT180 was the earlier marker for phosphorylated Tau and evident only in a subset of spines in Tau.P301L mice, while observed in most spines in Tau.4R mice (Fig. 6A,B). Both epitopes were absent in the brains of young transgenic YFP mice and in the brains of mice with a wild-type FVB genetic background (Fig. $6 D$; data not shown).

\section{Discussion}

To better understand the morphological counterparts of early changes in cognition in our different transgenic disease models, we analyzed dendritic spines by crossing them to YFP transgenic mice. This strategy was time-consuming and costly but allowed us to perform detailed comparative analysis of dendritic spines in 
Tau.P301L 1-2 months

A

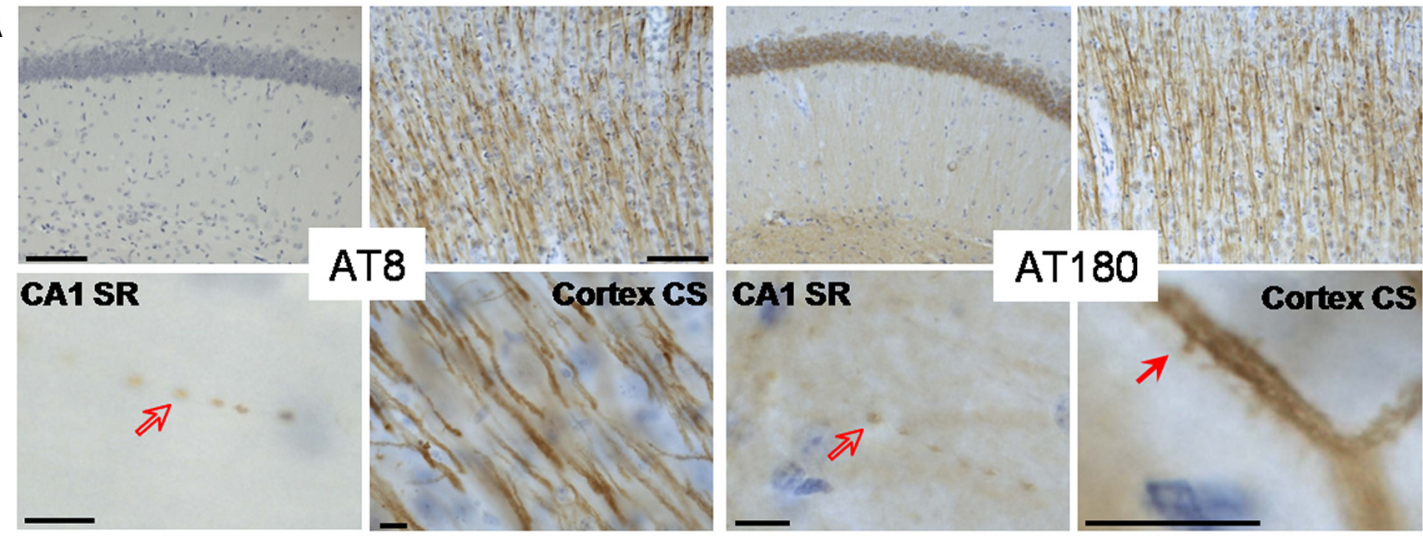

Tau.P301L 4-6 months

B
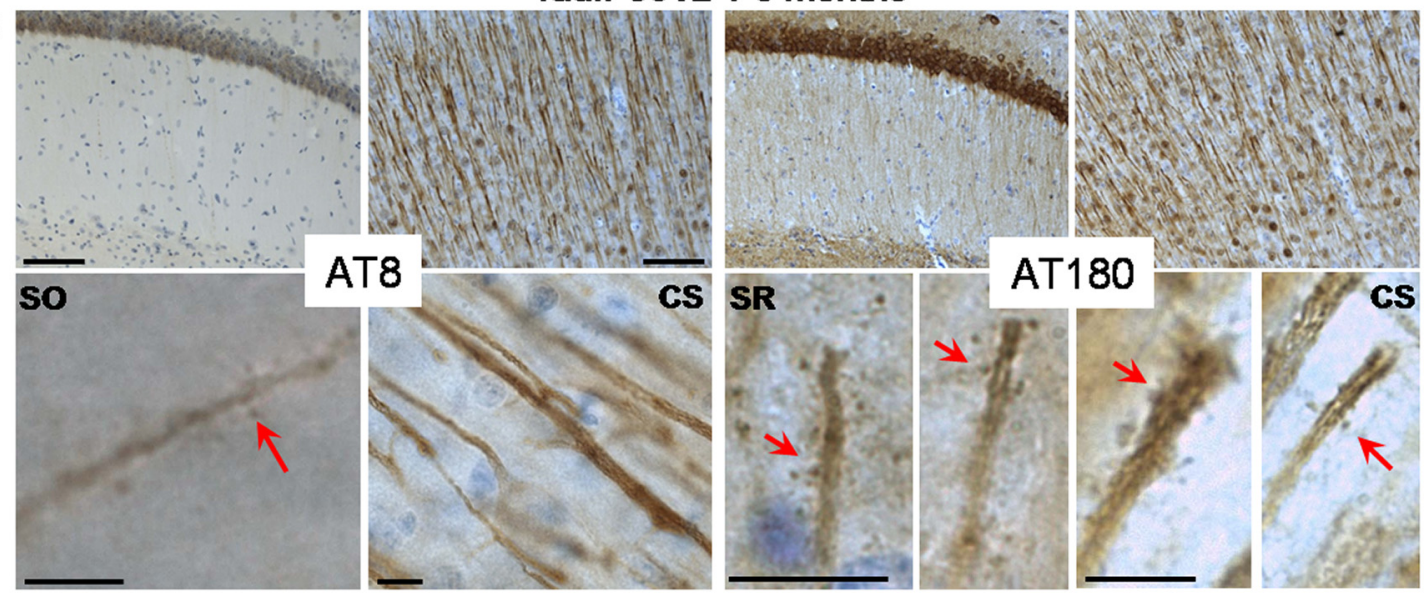

Tau.4R 4-6 months

C
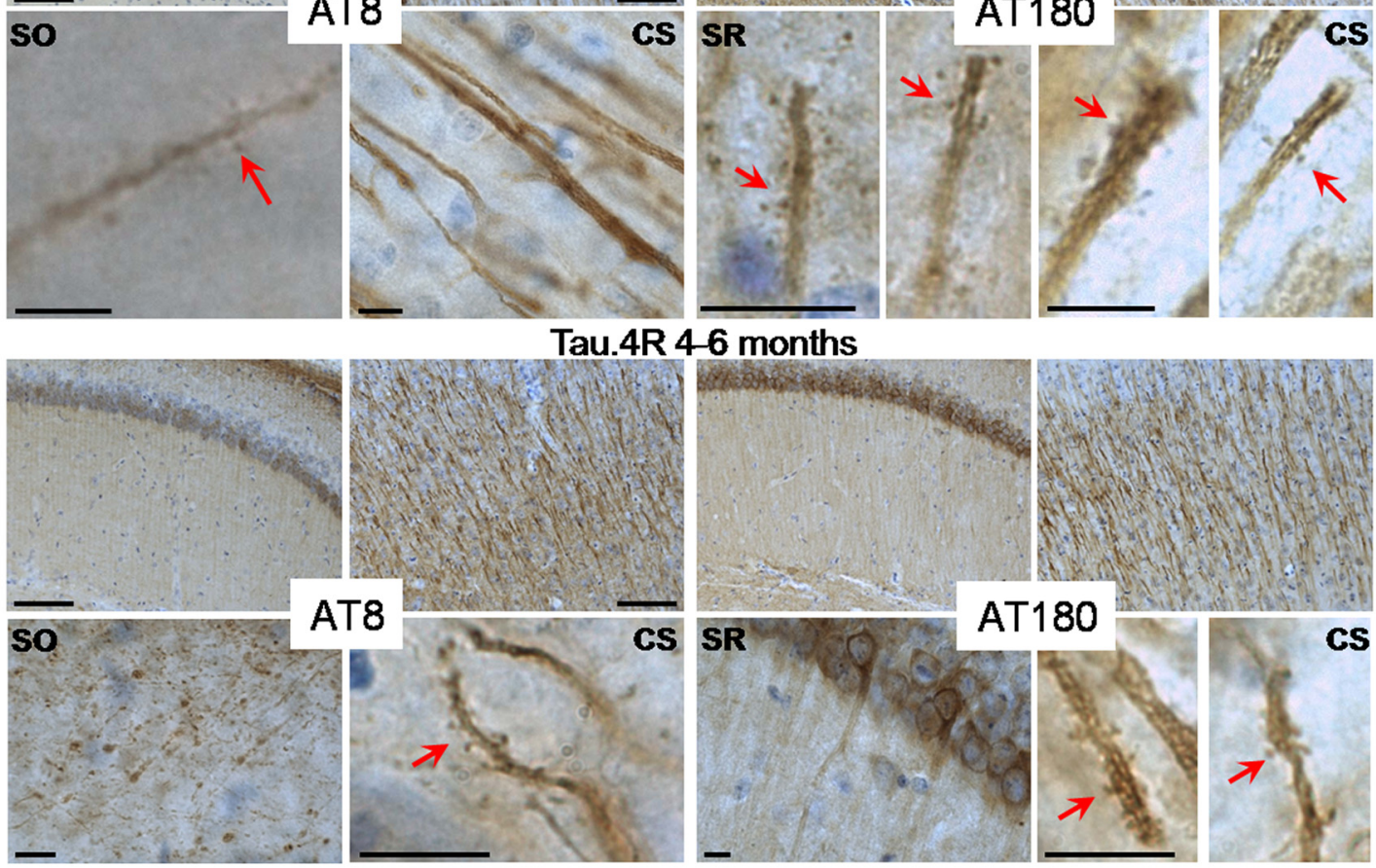

D
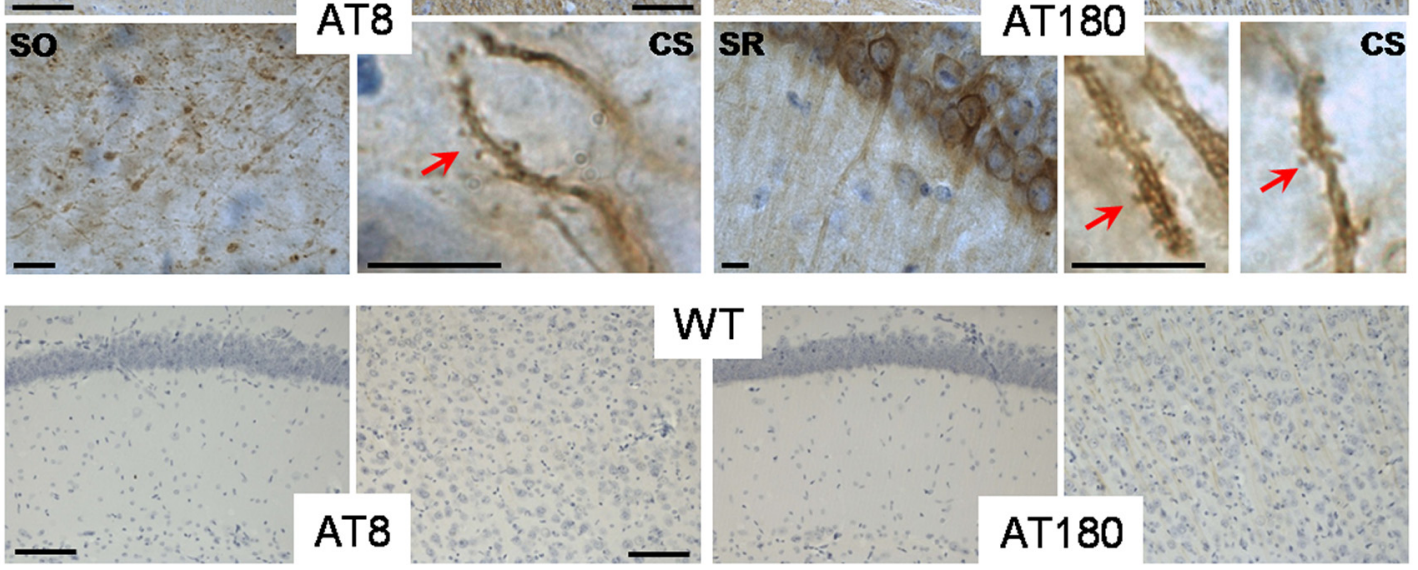

Figure 6. Localization of phosphorylated human Tau.4R and mutant Tau.P301L in dendritic spines. A, IHC with AT8 and AT180 reveals protein Tau in CA1 and cortex of young Tau.P301L mice. Note immunoreaction of AT8 in varicosities along dendrites in CA1 (bottom, labeled CA1 SR), of AT8 in dendrites, and of AT180 in dendrites and spines in CS (bottom, labeled CS). Scale bars: top, $100 \mu \mathrm{m}$; bottom, $10 \mu \mathrm{m}$. B, Distribution of AT8 and AT180 in CA1 and cortex of adult Tau.P301L mice. Note immunoreaction of AT8 and AT180 in dendrites and spines in CA1 (bottom, labeled CA1 S0/SR), while distribution in cortex is not different from that in young Tau.P301L mice. Scale bars: top, $100 \mu \mathrm{m}$; bottom, $10 \mu \mathrm{m}$. C, Distribution of AT8 and AT180 in CA1 and cortex of $4-6$-month-old Tau.4R brains. Note axonal immunoreaction of AT8 in $\mathrm{SO}$ and of AT180 in dendrites of CA1 neurons (bottom, labeled CA1 S0/SR). Both phospho-epitopes are detected in cortical dendritic spines (bottom, labeled (S). Scale bars: top, $100 \mu \mathrm{m}$; bottom, $10 \mu \mathrm{m}$. D, Absence of immunoreaction with AT8 (left) and AT180 (right) in brain of young wild-type mice. Scale bars, $100 \mu \mathrm{m}$. All images are from brain sections fixed according to Bouin. Red arrows indicate spines containing protein Tau. 
specified brain regions of all genotypes at different ages. Moreover, the technical and biological advantages were considerable: no manipulations of intracerebral injection of viral vectors were needed. Also evident was the advantage over ex vivo acute or organotypic sections, which requires Golgi staining, a technique that is demanding and variable in outcome. Finally, our approach allowed us to study effects of endogenous and transgenic protein Tau, and compare them at different ages under the same conditions, in the same brain regions, by the same techniques. Parameters of spines that were analyzed and relevant for synaptic plasticity include density, length, and maturation index, measured in hippocampus and frontal cortex relevant for tauopathies, including $\mathrm{AD}$.

Here, we focus on Tau.P301L mice as a model for tauopathy (Terwel et al., 2005; Boekhoorn et al., 2006; Dutschmann et al., 2010) and include some data on adult Tau.4R mice that develop axonopathy (Spittaels et al., 1999). Of note, the cognitive impairment of adult Tau.P301L mice (4-6 months) is preceded by a transient improvement in cognition at young age (1-2 months) (Boekhoorn et al., 2006), a characteristic that was unexplained until now.

\section{Protein Tau promotes dendritic spines}

Density of dendritic spines increased in the cortex of adult Tau.P301L mice, and in the cortex and hippocampus of adult Tau.4R mice, relative to wild-type mice, demonstrating that human protein Tau promotes spinogenesis. Nevertheless, in adult Tau.P301L mice, defective cognition is reflected in significantly shorter dendritic spines in the hippocampus, which was even more pronounced in the hippocampus and cortex of adult Tau.4R mice. Unfortunately, their early and severe axonopathy with associated motor defects precludes reliable cognitive testing and prohibits the correlative analysis of spines and cognition in Tau.4R mice.

With respect to cognition, the most remarkable and interesting result was the significant higher spine maturation index in CA1 and cortex of young Tau.P301L mice. These structural changes are the anatomical substrate that can underpin and explain the improved cognition and LTP of young Tau.P301L mice (Boekhoorn et al., 2006). In retrospect, this important conclusion can be extended to the improved cognition of our Tau.KOKI mice, which expressed human Tau.4R but at lower levels than Tau.4R mice, producing no motor problems (Sennvik et al., 2007). Tau.KOKI mice performed cognitively better, similar to young Tau.P301L mice, which we ascribed to their augmented neurogenesis, implying increased spinogenesis and/or maturation, completely in line with current observations.

Of note, even at 4-6 months, Tau.P301L mice are still pathologically presymptomatic because their terminal phase sets in at $\sim 7-8$ months with motor deficits, muscle wasting, and tauopathy, all progressing over a period of 4-6 weeks to end by upper airway dysfunction and premature death (Fig. 1) (Terwel et al., 2005, 2008; Dutschmann et al., 2010; Menuet et al., 2011; this study).

The combined data fully support the hypothesis that wildtype and mutant Tau similarly contribute to genesis and morphology of dendritic spines. Most interestingly, protein Tau acts on the characteristics of spines in opposite ways, depending on the age of the animal. Finally, the changes in spines closely correlate with the cognitive status of the Tau.P301L mice, resulting in improved for young mice and diminished for adult mice (Terwel et al., 2005; Boekhoorn et al., 2006). Intuitively, any MAP contributing to the generation of dendritic spines would be assumed to be located at the dendritic shaft and at the postsynaptic side of the spine. The above outcome was therefore unexpected because protein Tau is known mainly, if not solely, as an axonal MAP. The data support this hypothesis only if it is valid in pathology and not physiologically.

By extrapolation and comparison of data obtained in Tau.P301L and Tau.4R mice, we corroborate our thesis that, in pathology, wild-type Tau can be as effective as mutant Tau in causing dendritic problems and eventually neurodegeneration (Jaworski et al., 2009b, 2011). It is evident that wild-type protein Tau causes most tauopathies, including all cases of AD, the most frequent, albeit secondary tauopathy (Duyckaerts et al., 2009). Moreover, an important subset of FTDP-17 cases is caused by intronic MAPT mutations and express wild-type protein, which must be the obligatory cause of the disease. The fact that Tau.P301L, or a similar mutant, is needed in transgenic mice to develop tauopathy must be attributed to an extra, unknown characteristic. Equally important are levels of protein Tau.4R and Tau.3R that can tilt the balance from physiology to pathology, exemplified by sporadic tauopathies (Duyckaerts et al., 2009).

Conversely, the physiologically important outcome of our observations on the contribution of protein Tau to the genesis and maturation of spines, accentuates the major problem this research field is facing. The action of any protein on dendritic spines is intuitively attributed to its location at dendritic, postsynaptic sides, either in dendritic shafts or in evolving filopodia or spines. We evidently cannot exclude the possibility that axonal signals, mediated directly or indirectly by protein Tau, additionally or even preponderantly, contribute to the observed effects on dendritic spines. In the case of protein Tau, our expectation contrasted with the classic view of protein Tau as an exclusive axonal MAP, which obliged us to undertake extra experimental efforts to define the localization of protein Tau and its major phosphorylated isoforms in the brain of wild-type and transgenic mice.

\section{Pathologically, but not physiologically, protein Tau lodges in spines}

The finding that synaptosomes contain human Tau.P301L and phosphorylated isoforms is consistent with, but does not prove, the presence at synapses. Interestingly, endogenous mouse Tau was prominent in synaptosomal preparations isolated from wildtype mice, but markedly less and less phosphorylated than human Tau. On the other hand, because synaptosomes contain presynaptic and postsynaptic compartments, we went on to define the location of protein Tau in primary neurons and in brain sections.

In embryonic hippocampal neurons, either transfected or transduced with viral vectors or derived from transgenic mice, spines contained human protein Tau, which was readily demonstrated by immunocytochemistry. Pathologically, protein Tau is present in spines and its negative effects on spines, and by extension on synaptic plasticity and cognition, are caused by this abnormal postsynaptic localization. The next question is whether this pathological mislocalization is part of an exaggerated or a derailed physiological mechanism, i.e., whether protein Tau is physiologically also present in spines. The normal physiological function - if any - that Tau can exert as MAP in spines remains obscure because spines do not permanently contain microtubules (Jaworski et al., 2009a).

These questions, addressed in primary neurons from wildtype mice, were not answered conclusively: although we observed protein Tau in nearly all processes, colocalization with postsynaptic markers was rare. In vivo, standard IHC on free-floating sagittal or coronal mouse sections failed to distinctly reveal the 
presence of mouse or human Tau in dendritic spines. The extensive analysis of endogenous mouse and mutant human Tau by different methods of fixation, embedding, sectioning, antigen retrieval, and antibodies proved negative. Pretreatment of brain sections with alkaline phosphatase (Papasozomenos and Binder, 1987) improved detection of endogenous and human transgenic Tau in soma and dendrites, but dendritic spines remained unmarked for Tau.

Fixation according to Bouin (Trojanowski et al., 1989) improved visualization of actin filaments in spines. Nevertheless, mouse Tau was only detected in CA1 stratum radiatum of wildtype mice in presynaptic compartments of Schaffer collaterals docking onto proximal segments of dendrites from CA1 neurons (Binder et al., 1985). Consequently, while our data verify the axonal and presynaptic localization of mouse Tau (Dotti et al., 1987; Papasozomenos and Binder, 1987), they do not unequivocally demonstrate mouse Tau in dendritic spines in wild-type mice.

\section{Concluding remarks}

Our main finding that protein Tau, wild-type and mutant alike, directly affects formation, maturation, and morphology of dendritic spines in transgenic mice is evidenced by its postsynaptic location in dendritic spines. Mice expressing either wild-type or mutant human Tau revealed similar, but not identical, effects on density and length of dendritic spines, despite differences in phosphorylation and localization of Tau.

Interestingly, wild-type and mutant human Tau located differentially in the hippocampus, but similarly in cortical dendrites and spines. In the hippocampus, wild-type Tau.4R was mostly retained within axons, while mutant Tau.P301L accumulated in dendritic shafts and spines. The data thereby implicate regional differences in phosphorylation of protein Tau to contribute to subcellular localization and sorting, and to the characteristics of dendritic spines. These findings can relate to brain-regional, pathological, and clinical differences observed in tauopathy patients.

The combined data imply that Tau affects spine density and length from within both presynaptic and postsynaptic compartments. However, questions still remain about how Tau affects spine density and length from within postsynaptic compartments in normal physiological conditions because mouse Tau is not observed in dendritic spines. This observation is consistent with the finding that microtubules are absent in dendritic spines (Jaworski et al., 2009a), obviating any need for the presence of protein Tau or other MAPs in spines. Alternatively, the results question the contribution of protein Tau to the transport of the Src-kinase Fyn to the postsynaptic density under normal physiological conditions, but add considerable weight to the potential importance of protein Tau-Fyn interactions in pathology (Lee et al., 1998; Ittner et al., 2010; Zempel et al., 2010).

Finally, the documented presence of mutant protein Tau.P301L in postsynaptic compartments in the hippocampus, and the initial increased maturation of spines, demonstrates a beneficial effect of mutant Tau to explain the improved cognition of young Tau.P301L mice (Boekhoorn et al., 2006). The transient nature leads us to conclude that mutations in protein Tau demonstrate evolutionary attempts to improve spinogenesis and maturation, and thereby cognitive ability. The subsequent cognitive demise and tauopathy progressing with age, in patients and in mutant Tau mice alike, evidently prevent the fixation of this and similar mutations in the gene coding for protein Tau in the population.

\section{References}

Banker GA, Cowan WM (1977) Rat hippocampal neurons in dispersed cell culture. Brain Res 126:397-342.

Binder LI, Frankfurter A, Rebhun LI (1985) The distribution of tau in the mammalian central nervous system. J Cell Biol 101:1371-1378.

Bittner T, Fuhrmann M, Burgold S, Ochs SM, Hoffmann N, Mitteregger G, Kretzschmar H, LaFerla FM, Herms J (2010) Multiple events lead to dendritic spine loss in triple transgenic Alzheimer's disease mice. PLoS One 5:e15477.

Boekhoorn K, Terwel D, Biemans B, Borghgraef P, Wiegert O, Ramakers GJ, de Vos K, Krugers H, Tomiyama T, Mori H, Joels M, van Leuven F, Lucassen PJ (2006) Improved long-term potentiation and memory in young Tau-P301L transgenic mice before onset of hyperphosphorylation and tauopathy. J Neurosci 26:3514-3523.

Braak H, Braak E (1991) Neuropathological stageing of Alzheimer-related changes. Acta Neuropathol 82:239-259.

Braak H, Del Tredici K (2011) The pathological process underlying Alzheimer's disease in individuals under thirty. Acta Neuropathol 121:171-181.

Delacourte A (2008) Tau pathology and neurodegeneration: an obvious but misunderstood link. J Alzheimers Dis 14:437-440.

Delacourte A, Buée L (2000) Tau pathology: a marker of neurodegenerative disorders. Curr Opin Neurol 13:371-376.

Dickstein DL, Brautigam H, Stockton SD Jr, Schmeidler J, Hof PR (2010) Changes in dendritic complexity and spine morphology in transgenic mice expressing human wild-type tau. Brain Struct Funct 214:161-179.

Dotti CG, Banker GA, Binder LI (1987) The expression and distribution of the microtubule-associated proteins tau and microtubule-associated protein 2 in hippocampal neurons in the rat in situ and in cell culture. Neuroscience 23:121-130.

Dutschmann M, Menuet C, Stettner GM, Gestreau C, Borghgraef P, Devijver H, Gielis L, Hilaire G, Van Leuven F (2010) Upper airway dysfunction of Tau.P301L mice correlates with tauopathy in midbrain and pontomedullary brainstem nuclei. J Neurosci 30:1810-1821.

Duyckaerts C (2011) Tau pathology in children and young adults: can you still be unconditionally Baptist? Acta Neuropathol 121:145-147.

Duyckaerts C, Delatour B, Potier MC (2009) Classification and basic pathology of Alzheimer disease. Acta Neuropathol 118:5-36.

Feng G, Mellor RH, Bernstein M, Keller-Peck C, Nguyen QT, Wallace M, Nerbonne JM, Lichtman JW, Sanes JR (2000) Imaging neuronal subsets in transgenic mice expressing multiple spectral variants of GFP. Neuron 28:41-51.

Härtig W, Oklejewicz M, Strijkstra AM, Boerema AS, Stieler J, Arendt T (2005) Phosphorylation of the tau protein sequence 199-205 in the hippocampal CA3 region of Syrian hamsters in adulthood and during aging. Brain Res 1056:100-104.

Härtig W, Stieler J, Boerema AS, Wolf J, Schmidt U, Weissfuss J, Bullmann T, Strijkstra AM, Arendt T (2007) Hibernation model of tau phosphorylation in hamsters: selective vulnerability of cholinergic basal forebrain neurons -implications for Alzheimer's disease. Eur J Neurosci 25:69-80.

Hering H, Sheng M (2001) Dendritic spines: structure, dynamics and regulation. Nat Rev Neurosci 2:880-888.

Hoover BR, Reed MN, Su J, Penrod RD, Kotilinek LA, Grant MK, Pitstick R, Carlson GA, Lanier LM, Yuan LL, Ashe KH, Liao D (2010) Tau mislocalization to dendritic spines mediates synaptic dysfunction independently of neurodegeneration. Neuron 68:1067-1081.

Ingram EM, Spillantini MG (2002) Tau gene mutations: dissecting the pathogenesis of FTDP-17. Trends Mol Med 8:555-562.

Ittner LM, Ke YD, Delerue F, Bi M, Gladbach A, van Eersel J, Wölfing $\mathrm{H}$, Chieng BC, Christie MJ, Napier IA, Eckert A, Staufenbiel M, Hardeman E, Götz J (2010) Dendritic function of tau mediates amyloid-beta toxicity in Alzheimer's disease mouse models. Cell 142:387-397.

Jaworski J, Kapitein LC, Gouveia SM, Dortland BR, Wulf PS, Grigoriev I, Camera P, Spangler SA, Di Stefano P, Demmers J, Krugers H, Defilippi P, Akhmanova A, Hoogenraad CC (2009a) Dynamic microtubules regulate dendritic spine morphology and synaptic plasticity. Neuron 61:85-100.

Jaworski T, Dewachter I, Lechat B, Croes S, Termont A, Demedts D, Borghgraef P, Devijver H, Filipkowski RK, Kaczmarek L, Kügler S, Van Leuven F (2009b) AAV-tau mediates pyramidal neurodegeneration by cell-cycle re-entry without neurofibrillary tangle formation in wild-type mice. PLoS One 4:e7280.

Jaworski T, Lechat B, Demedts D, Gielis L, Devijver H, Borghgraef P, Duimel 
H, Verheyen FK, Kügler S, Van Leuven F (2011) Dendritic degeneration and neurovascular defects precede AAV-Tau-mediated neuronal loss. Am J Pathol 179:2001-2015.

Kenessey A, Yen SH (1993) The extent of phosphorylation of fetal tau is comparable to that of PHF-tau from Alzheimer paired helical filaments. Brain Res 629:40-46.

Künzi V, Glatzel M, Nakano MY, Greber UF, Van Leuven F, Aguzzi A (2002) Unhampered prion neuroinvasion despite impaired fast axonal transport in transgenic mice overexpressing four-repeat tau. J Neurosci 22:74717477.

Lee G, Newman ST, Gard DL, Band H, Panchamoorthy G (1998) Tau interacts with src-family non-receptor tyrosine kinases. J Cell Sci 111: 3167-3177.

Ludolph AC, Kassubek J, Landwehrmeyer BG, Mandelkow E, Mandelkow EM, Burn DJ, Caparros-Lefebvre D, Frey KA, de Yebenes JG, Gasser T, Heutink P, Höglinger G, Jamrozik Z, Jellinger KA, Kazantsev A, Kretzschmar H, Lang AE, Litvan I, Lucas JJ, McGeer PL, et al. (2009) Tauopathies with parkinsonism: clinical spectrum, neuropathologic basis, biological markers, and treatment options. Eur J Neurol 16:297-309.

Menuet C, Borghgraef P, Matarazzo V, Gielis L, Lajard AM, Voituron N, Gestreau C, Dutschmann M, Van Leuven F, Hilaire G (2011) Raphé tauopathy alters serotonin metabolism and breathing activity in terminal Tau.P301L mice: possible implications for tauopathies and Alzheimer's disease. Respir Physiol Neurobiol 178:290-303.

Moechars D, Dewachter I, Lorent K, Reversé D, Baekelandt V, Naidu A, Tesseur I, Spittaels K, Haute CV, Checler F, Godaux E, Cordell B, Van Leuven F (1999) Early phenotypic changes in transgenic mice that overexpress different mutants of Amyloid Precursor Protein in brain. J Biol Chem 274:6483-6492.

Papasozomenos SC, Binder LI (1987) Phosphorylation determines two distinct species of Tau in the central nervous system. Cell Motil Cytoskeleton $8: 210-226$.

Penzes P, Cahill ME, Jones KA, VanLeeuwen JE, Woolfrey KM (2011) Dendritic spine pathology in neuropsychiatric disorders. Nat Neurosci 14:285-293.

Pérez-Otaño I, Luján R, Tavalin SJ, Plomann M, Modregger J, Liu XB, Jones EG, Heinemann SF, Lo DC, Ehlers MD (2006) Endocytosis and synaptic removal of NR3A-containing NMDA receptors by PACSIN1/syndapin1. Nat Neurosci 9:611-621.

Planel E, Bretteville A, Liu L, Virag L, Du AL, Yu WH, Dickson DW, Whittington RA, Duff KE (2009) Acceleration and persistence of neurofibrillary pathology in a mouse model of tauopathy following anesthesia. FASEB J 23:2595-2604.

Rocher AB, Crimins JL, Amatrudo JM, Kinson MS, Todd-Brown MA, Lewis
J, Luebke JI (2010) Structural and functional changes in tau mutant mice neurons are not linked to the presence of NFTs. Exp Neurol 223:385-393.

Sennvik K, Boekhoorn K, Lasrado R, Terwel D, Verhaeghe S, Korr H, Schmitz C, Tomiyama T, Mori H, Krugers H, Joels M, Ramakers GJ, Lucassen PJ, Van Leuven F (2007) Tau-4R suppresses proliferation and promotes neuronal differentiation in the hippocampus of tau knockin/knockout mice. FASEB J 21:2149-2161.

Spittaels K, Van den Haute C, Van Dorpe J, Bruynseels K, Vandezande K, Laenen I, Geerts H, Mercken M, Sciot R, Van Lommel A, Loos R, Van Leuven F (1999) Prominent axonopathy in the brain and spinal cord of transgenic mice overexpressing four-repeat human tau protein. Am J Pathol 155:2153-2165.

Spittaels K, Van den Haute C, Van Dorpe J, Geerts H, Mercken M, Bruynseels K, Lasrado R, Vandezande K, Laenen I, Boon T, Van Lint J, Vandenheede J, Moechars D, Loos R, Van Leuven F (2000) Glycogen synthase kinase-3beta phosphorylates protein tau and rescues the axonopathy in the CNS of human four-repeat tau transgenic mice. J Biol Chem 275:41340-41349.

Tackenberg C, Brandt R (2009) Divergent pathways mediate spine alterations and cell death induced by amyloid- $\beta$, wild-type tau, and R406W tau. J Neurosci 29:14439-14450.

Takuma H, Arawaka S, Mori H (2003) Isoforms changes of tau protein during development in various species. Brain Res Dev Brain Res 142:121-127.

Terwel D, Lasrado R, Snauwaert J, Vandeweert E, Van Haesendonck C, Borghgraef P, Van Leuven F (2005) Changed conformation of mutant tau-P301L underlies the moribund tauopathy, absent in progressive, nonlethal axonopathy of tau- $4 \mathrm{R} / 2 \mathrm{~N}$ transgenic mice. J Biol Chem 280:3963-3973.

Terwel D, Muyllaert D, Dewachter I, Borghgraef P, Croes S, Devijver H, Van Leuven F (2008) Amyloid activates GSK3 $\beta$ to aggravate neuronal tauopathy in bigenic mice. Am J Pathol 172:786-798.

Thies E, Mandelkow EM (2007) Missorting of tau in neurons causes degeneration of synapses that can be rescued by the kinase MARK2/Par-1. J Neurosci 27:2896-2907.

Trojanowski JQ, Schuck T, Schmidt ML, Lee VM (1989) Distribution of Tau proteins in the normal human central and peripheral nervous system. J Histochem Cytochem 37:209-215.

Zempel H, Thies E, Mandelkow E, Mandelkow EM (2010) A $\beta$ oligomers cause localized $\mathrm{Ca}^{2+}$ elevation, missorting of endogenous Tau into dendrites, Tau phosphorylation, and destruction of microtubules and spines. J Neurosci 30:11938-11950. 